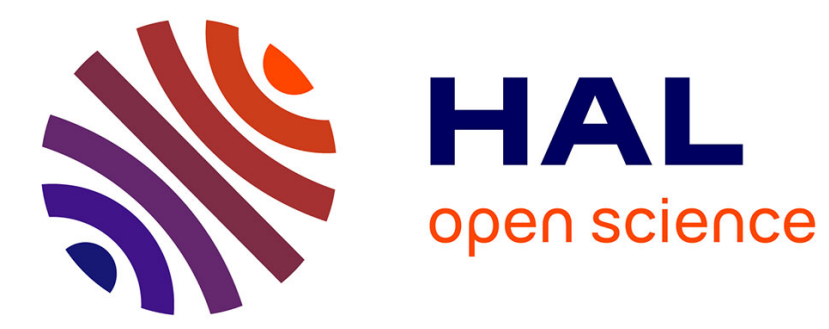

\title{
Low Temperature Plasma Enhanced CVD Synthesis of Piezoactive ZnO Films
}

\author{
T. Tabenskaya, V. Ovsyannikov, E. Mazurenko
}

\section{To cite this version:}

T. Tabenskaya, V. Ovsyannikov, E. Mazurenko. Low Temperature Plasma Enhanced CVD Synthesis of Piezoactive ZnO Films. Journal de Physique IV Proceedings, 1995, 05 (C5), pp.C5-711-C5-715. 10.1051/jphyscol:1995586 . jpa-00253948

\section{HAL Id: jpa-00253948 https://hal.science/jpa-00253948}

Submitted on 1 Jan 1995

HAL is a multi-disciplinary open access archive for the deposit and dissemination of scientific research documents, whether they are published or not. The documents may come from teaching and research institutions in France or abroad, or from public or private research centers.
L'archive ouverte pluridisciplinaire HAL, est destinée au dépôt et à la diffusion de documents scientifiques de niveau recherche, publiés ou non, émanant des établissements d'enseignement et de recherche français ou étrangers, des laboratoires publics ou privés. 


\title{
Low Temperature Plasma Enhanced CVD Synthesis of Piezoactive ZnO Films
}

T.V. Tabenskaya, V.P. Ovsyannikov and E.A. Mazurenko

Institute of General and Inorganic Chemistry of National Academy of Sciences of Ukraine, 32/34 Palladina prosp., Kiev-142, UA-252142, Ukraine

\begin{abstract}
Plasma-enhanced organometallic chemical vapour deposition process has been developed to obtain piezoelectric $\mathrm{ZnO}$ films with a highly preferred orientation of the crystallites on sapphire and on $\mathrm{SiO}_{2} / \mathrm{Si}$ substrates. The volatile organic precursor of zinc acetylacetonate $\mathrm{Zn}(\mathrm{AA})_{2}$ decomposes under r.f. discharge plasma at low temperature in controlled atmosphere of $\mathrm{Ar}+\mathrm{O}_{2}$ gas mixture.

The optimal deposition conditions of high quality $\mathrm{ZnO}$ film were deduced and investigated. The films obtained have high resistivity and transparency.
\end{abstract}

\section{INTRODUCTION}

$\mathrm{ZnO}$ thin films due to their interesting properties have a lot of different applications. For example, films with high conductivity and transparency in the visible spectral range can be used as transparent electrodes [1-3], while highly oriented films with low conductivity can be used in acousto- and electrooptic devices $[4,5]$.

Techniques for zinc oxide thin films deposition such as spray pyrolysis $[3,6]$, sputtering $[1,2]$, various kinds of chemical vapour deposition (CVD) $[8,9,10]$ chemical deposition from solutions [1] are described

Plasma enhanced metalorganic chemical vapor deposition (PE MOCVD) allows to prepare high quality $\mathrm{ZnO}$ films at lower temperatures than usual CVD techniques [12,13]. However such technologically unsuitable compounds as diethylzinc (DEZ) and dimethylzinc (DMZ) are usually used as precursors in CVD process.

In this paper we discuss the PE MOCVD of $\mathrm{ZnO}$ films with a highly preferred orientation. Zinc acetylacetonate $\mathrm{Zn}(\mathrm{AA})_{2}(\mathrm{AA}=$ acetylacetonate) used as precursor is advantageous with respect to early used reagents due to its non-toxicity, non-inflammability and non-explodity.

\section{FILMS PREPARATION}

Figure 1 shows a scheme of the experimental setup. It consists of a continuously pumped horizontal quartz tube placed between copper plates on which r.f. power $(13,56 \mathrm{MHz})$ is applied to produce plasma in the reaction chamber and to dissociate $\mathrm{Zn}(\mathrm{AA})_{2}$ vapor. The base unit was equipped with a resistiveheated cylindrical evaporator where $\operatorname{Zn}(\mathrm{AA})_{2}$ powder was placed in a quartz ampule with calibrated orifice $(\mathrm{d}=0.2-1 \mathrm{~mm})$. 


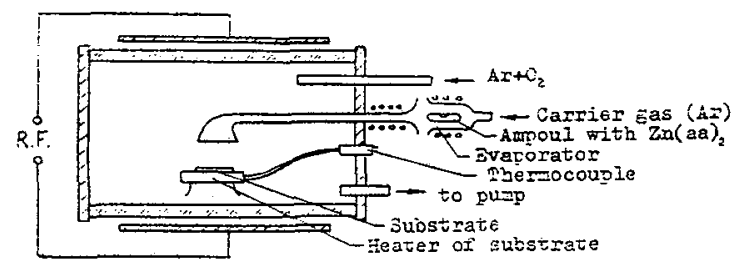

Figure 1: Schematic representation of the PEMOCVD apparatus

The substrate was chemically purified under plasma discharge power of $\mathrm{W}_{\mathrm{p}}=700 \mathrm{~W}$ and system pressure of $\mathrm{P}=0.2 \mathrm{mTorr}$ before the deposition. When the reaction chamber is evacuated to the base pressure of $100 \mathrm{mTorr}$ and mixture of $\mathrm{Ar}+\mathrm{O}_{2}$ is introduced into discharge tube, the pressure reaches the value of 200$500 \mathrm{~m}$ Torr. The total pressure during the film deposition increased to $0.4-1.4$ Torr due to evaporation of organometalic compound.

The PEMOCVD experiments show that the film properties are extremely affected by deposition conditions. The dependence of the characteristics of $\mathrm{ZnO}$ films grown on crystalline sapphire $(001)$, silicon (100) and $\mathrm{SiO}_{2} / \mathrm{Si}$ substrates on the technological parameters of $\mathrm{PE} \mathrm{MOCVD} \mathrm{process} \mathrm{is} \mathrm{investigated.} \mathrm{The}$ temperature of substrates Ts has been varied from 50 to $250^{\circ} \mathrm{C}$ and r.f. power from 200 to $600 \mathrm{~W}$.

\section{RESULTS AND DISCUSSION}

The study of chemical composition of ZnO films using Auger spectrometer "JAMP-10S" and X-ray microprobe analyzer "JCXA-733" showed the absence of impurities, including carbon. Error of both methods was less than 0.1 at.\%. Auger spectroscopy was also used to determine the elemental distribution profiles. Figure 2 shows the elemental distribution profiles in zinc oxide/silicon sample. A transition region (III) where chemical composition changes can be seen. The existence of a transition region between the film and the substrate may be explained considering a solidphase chemical reaction of the system $\mathrm{ZnO} / \mathrm{Si}$ [14]. Within this region nearly $20 \mathrm{~nm}$ wide a change of relative oxygen and zinc contents takes place.

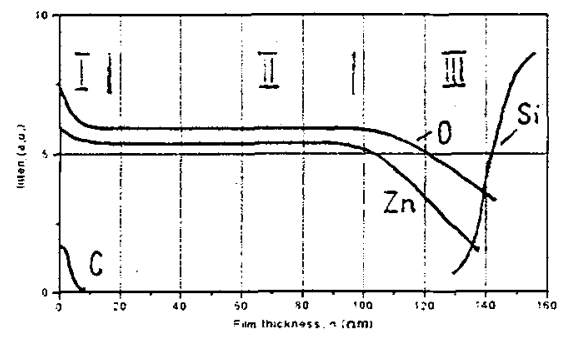

Figure 2: Element distribution profile in the $\mathrm{ZnO} / \mathrm{Si}$ sample (h:film thickness)

The existence of a transition region was also verified by photoluminescence measurements of the $\mathrm{ZnO}$ films deposited on sapphire. As a result of nitrogen laser excitation $\left(\lambda_{\mathrm{ex}}=338 \mathrm{~nm}\right)$, the photoluminescence spectrum of the sample taken on the film side is considerably different from that obtained fon the substrare side (Fig.3). In the last case the evident maxima displacement to yellow-orange region may be explained by nonstoichiometricity of chemical composition and by structural changes in the transition area [15]. 


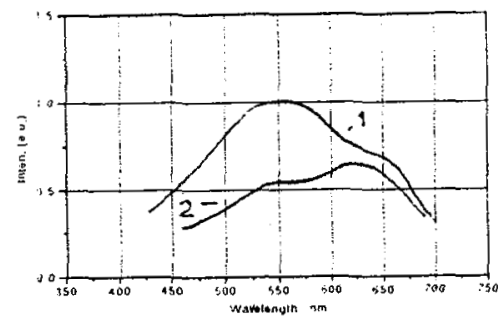

Figure 3: Photoluminescence spectrum of $\mathrm{ZnO}$ film on sapphire (001) from the side of film (1) and substrate (2)

As-deposited $\mathrm{ZnO}$ films have a polycrystalline structure. Phase analysis carried out by $\mathrm{X}$-ray and electron-diffraction methods showed the presence of a single phase corresponding to the hexagonal $\mathrm{ZnO}$ structure. Small-angle X-ray diffraction spectrum of the film deposited at gas carrier flow rate of $55 \mathrm{ml} / \mathrm{min}$ is shown in Figure 4b. The diffractogram reveales pronounced (001) texture in the film with preferred orientation of crystallites along $c$ axis, normal to the substrate surface [16]. The only one diffraction peak (002) located at $2 \theta=34.5^{\circ}$ is observed. On the other hand (101) and (100) peaks at $2 \theta=36.2^{\circ}$ and $2 \theta=31.7^{\circ}$ respectively are indicated for the films deposited at gas carrier flow rate of $55 \mathrm{ml} / \mathrm{min}$ (Fig. $4 \mathrm{a}$ ).
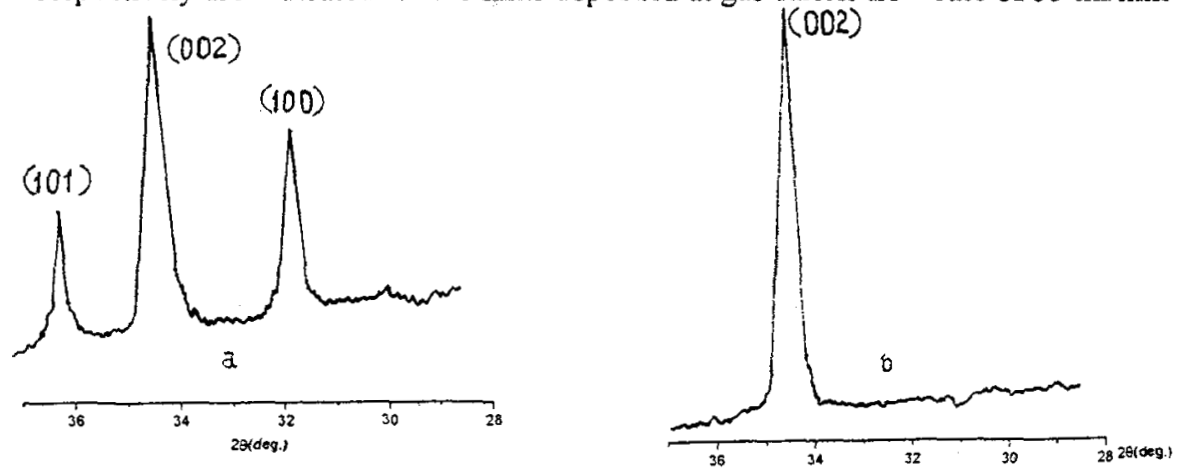

Figure 4: $\mathrm{X}$-ray diffraction spectra of $\mathrm{ZnO}$ thin films deposited on sapphire substrates at r.f.power of $380 \mathrm{~W}$, substrate temperature of $200^{\circ} \mathrm{C}$, pressure in reaction chamber of $500 \mathrm{mTorr}$, Ar flow rate $90 \mathrm{ml} / \mathrm{min}$ (a); $55 \mathrm{ml} / \mathrm{min}$ (b)

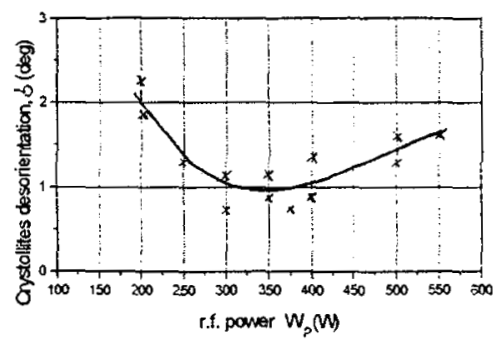

Figure 5: The degree of crystallites disorientation $\sigma$ in $\mathrm{ZnO}$ films on sapphire as a function of r.f.power $\mathrm{W}_{\mathrm{p}} . \mathrm{T}_{\mathrm{s}}=220^{\circ} \mathrm{C}$; $\mathrm{P}=450 \mathrm{mTorr} ; \mathrm{Q}=55 \mathrm{ml} / \mathrm{min}$. 
The crystallographic orientation of deposited $\mathrm{ZnO}$ film was essentially determined by the technological parameters such as the gas carrier flow rate $Q$ (Fig.4), the r.f. power $W_{p}$ (fig. 5 ), the substrate temperature Ts and the pressure in reaction chamber P (Fig.6).

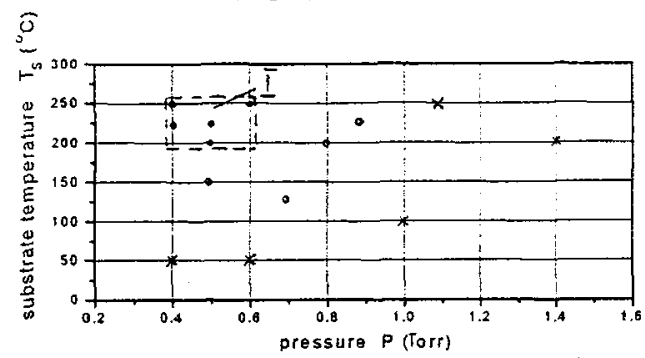

Figure 6: The degree of crystallites disorientation $\sigma$ in $\mathrm{ZnO}$ films on sapphire substates as a function of pressure $\mathrm{P}$ and substrate temperature $T_{s}, W_{p}=350 \mathrm{~W} ; \mathrm{Q}=50 \mathrm{ml} / \mathrm{min}$. $\mathrm{x}$-amorphous film;-low textured film; -high textured film (I)

As it follows from the $\mathrm{X}$-ray diffraction pattern, the optimal technoiogical conditions of $\mathrm{ZnO}$ films growth by PEMOCVD are: $T_{s}=200-250^{\circ} \mathrm{C}, W_{p}=250-400 \mathrm{~W}, Q=50-60 \mathrm{ml} / \mathrm{min}, P=400-600 \mathrm{mTorr}$. X-ray diffraction spectrum of $\mathrm{ZnO}$ film deposited on sapphire under these optimum parameters is shown in Fig. $4 b$. The films deposited on silicon substrates has no texture in agreement with literature data. Preoxidized silicon substrates were used to obtain textured layers.

The deposited films show a resistivity as high as $10^{8} \mathrm{Ohm} \cdot \mathrm{cm}$ owing to their rather good stoichiometry. Dielectric strength of $\mathrm{ZnO}$ films of $1 \mu \mathrm{m}$ thick is $\sim 10^{6} \mathrm{~V} / \mathrm{cm}$.

Optical measurments ("PYE UNICAM-8800" spectrophotometer) show that transmission of $0.8 \mu \mathrm{m}$ thick $\mathrm{ZnO}$ films is very similar to that of semiconductor materials: step-by-step change in transmission coefficient takes place (Fig.7) and a high transmission region (over 90\%) can be seen. Upon change of film structure from polycrystalline with highly preferred orientation to amorphous the transformation of the form of fundamental absorption edge from steplike to smeared is observed.

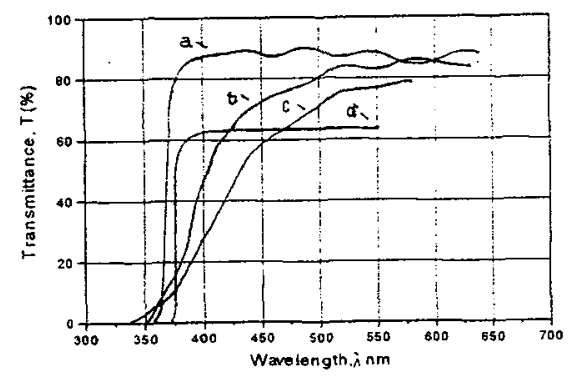

Figure 7: Optical transmission spectra of high textured (a), low textured (b), amorphous (c) $\mathrm{ZnO}$ film and $\mathrm{ZnO}$ single crystal of thickness $1.5 \mathrm{~mm}(\mathrm{~d})$

At $\lambda=630 \mathrm{~nm}$ the refractive index of film is equal to 1.97 . Experimental studies of optical losses in $\mathrm{ZnO}$ films carried out on the basis of waveguide effect of light extending allowed us to determine optical attenuation in planar waveguide to be less than $2 \mathrm{~dB} / \mathrm{cm}$.

Piezoelectric modulus $\mathrm{d}$ of the obtained films was determined by dynamical method [17] using etalon sample. Its magnitude $d_{33}=6-7 \cdot 10^{-12} \mathrm{C} / \mathrm{N}$ is close to the same characteristic of monocrystalline sample $\mathrm{ZnO}$. 


\section{CONCLUSIONS}

High quality piezoelectric $\mathrm{ZnO}$ films were deposited on sapphire and $\mathrm{SiO}_{2} / \mathrm{Si}$ substrates at low temperature using plasma-enhanced chemical vapor deposition and zinc acetylacetonate as a precursor. The film deposited under optimal technological parameters were uniform and had highly preferred orientation of crystallites. High piezoelectric and optical characteristics of films are essential for their application in acuosto-optical devices.

The proposed method of $\mathrm{ZnO}$ films synthesis could be attractive for deposition on partially formed structures with developed surface relief and on materials which do not allow high temperature influence.

\section{REFERENCES}

[1] K.Tominaga, K.Kuroda and O.Tada, Jpn. J.Appl. Phys. 27(7)(1988) 1176.

[2] T.Minami, H.Nanto and S. Takata, Thin Solid Films 124(1985) 43.

[3] S.Major,A.Banarjee and K.L.Chopra, Thin Solid Films 108(1983) 333.

[4] J.M.Hammer, D.J.Channin and T.M. Duffy, Appl.Phys.Lett. 23(1973) 176.

[5] F.S.Hickernell, J.E.E.E. Trans. Sonics and Ultrasonics 32(1985) 621.

[6]C.Eberspacher, A.L.Fahernbruch and R.H.Bube, Thin Solid Films 136(1986) 1.

[7] A. Valentini, A. Quirini and L.Vasanelli, Thin Solid Films 176(1989) L167.

[8] F.Z.Omar, Khan and Paul O'Brien, Thin Solid Films 173(1989) 95.

[9] M.Shimidzu, T. Shiosaki and A.Kawabata, J.Crytal Growth 57(1982) 94.

[10] S.Basu and A.Dutta, "Room temperature hydrogen sensors based on $\mathrm{ZnO}$ ", Int. Conf. on electronic materials, Hsinchu, Taiwan, Dec. 19-21,1994, p.96

[11] M.Ristov, Gj. Sinadinovski and I.Grozdanov, Thin Solid Films 149(1987) 65.

[12] A.Sherman, Thin Solid Films 113(1984) 135.

[13] M.Shimizu, Y.Matsueda and T.Shiosaki, J. Crystal Growth 71(1985) 209.

[14] M.S.Raven, M.H.T. Al-Sinaid and S.J.Owen, Thin Solid Films 71(1980) 23.

[15] J.Petrov, V. Orlinov, Thin Solid Films 120(1984) 55.

[16] O.Nennewitz, H.Schmidt, J.Pezold . "X-Ray Diffraction Analysis of RTP Anneled Thin ZnO Films". 4-th Int. Symp. on Trends and New Applications in Thin Films - TATF'94, Dresden. March 7-11, 1994, pp. 666-669

[17] R. Gerhard-Multhaupt, G.M.Sessler and J.E.West, J.Appl. Phys. 55(1984) 2769. 